\title{
Os capitais no Século XXI: um diálogo crítico entre Thomas Piketty e Pierre Bourdieu ${ }^{1}$
}

\author{
The capitals in XXI Century: a critical dialogue \\ between Thomas Piketty and Pierre Bourdieu
}

\section{João Henrique Salles Jung*1}

Palavras-chave: O Capital no Século XXI; Thomas Piketty; Pierre Bourdieu; Poder Simbólico; Desigualdade.

Keywords: The Capital in XXI Century; Thomas Piketty; Pierre Bourdieu; Symbolic Power; Inequality.
Resumo: Este artigo visa tecer um diálogo crítico Pierre Bourdieu e Thomas Piketty. Propõe-se uma crítica ao determinismo econômico realizado por Piketty e seus críticos na compreensão da desigualdade; utiliza-se, para isto, a obra de Bourdieu. Objetiva-se a absorção de elementos sociológicos presentes na obra de Pierre Bourdieu em vias de tratar a desigualdade como um fenômeno social, que requer um método de análise para além do economicismo. Através de uma mediação filosófica, compreende-se que a junção epistêmica de elementos simbólicos e materiais permite um melhor entendimento sobre a desigualdade no século XXI.

\begin{abstract}
This article aims to construct a critical dialogue between Pierre Bourdieu and Thomas Piketty. We propose a critic to the economic determinism perceived in Piketty and on his criticizers, thus Pierre Bourdieu is picked as a support to inequality comprehension. We absorb sociological elements within Pierre Bourdieu's works aiming to analyze inequality as a social phenomenon, which demands an analysis method beyond economism. Through a philosophical mediation, we assume that symbolic and material dimensions united allows a better understanding about inequality in the XXI Century.
\end{abstract}

\section{Introdução}

A obra $O$ Capital no Século XXI, de Thomas Piketty (2014), logrou reconhecimento que há muito não se via em relação a um livro; se tornou um best-seller que atraiu desde o público leigo até economistas e demais especialistas. Mais recentemente, em 2019 o economista lançou Capital

\footnotetext{
${ }^{1}$ Recebido em 24/02/2021. Aceito em 13/07/2021.

*1. Doutorando e Mestre em Filosofia pela PUCRS; bacharel em Relações Internacionais (ESPM) e graduando em Ciências Sociais (UFRGS). E-mail: joaojung@outlook.com.

2 Agradeço aos pareceristas anônimos pelas ricas sugestões. Do mesmo modo, sou grato ao Prof. Dr. Norman Madarasz pelos diálogos que me estimularam a escrever este artigo.
} 
et Ideologie, obra que ganhou sua versão brasileira em 2020. Para o bem e para o mal, Piketty chamou a atenção a um tema extremamente relevante na realidade contemporânea, a desigualdade. Ao realizar um extenso - e intenso levantamento de dados, o economista francês se propôs a levar o debate sobre desigualdade a um outro nível, no que argumenta ser tal assunto, até então, abordado com insuficiência empírica. De entusiastas à críticos, O Capital no Século XXI foi amplamente resenhada e comentada, fazendo parte do debate acadêmico e político; o mesmo panorama se desenha em relação ao Capital e Ideologia.

A intenção deste artigo é trazer a crítica aos trabalhos de Piketty (2014; 2020) para além do viés econômico; defende-se que a adoção de uma abordagem sociológica da questão pode trazer maior robustez à base teórica proposta por Piketty. Isso se dá justamente pelo fato de a teoria construída pelo economista, em vias de viabilizar a interpretação dos dados coletados, ser o principal alvo de críticas ao seu trabalho, como é possível verificar em Varoufakis (2014), Husson (2014), Jean-Philippe Delsol (2017), entre outros. Desta forma, o intuito aqui é demonstrar que a desigualdade não pode ser explicada através do determinismo econômico ${ }^{3}$, pois há uma série de elementos que se interseccionam para a produção de um efeito social como a desigualdade.

O título então proposto, "Os capitais no Século XXI: um diálogo crítico entre Thomas Piketty e Pierre Bourdieu" de antemão demonstra que a análise do fenômeno da desigualdade necessita de elementos para além do capital, tido na leitura mais rudimentar como o que aqui será denominado capital econômico. É através do arcabouço intelectual de outro pensador francês, o sociólogo e filósofo Pierre Bourdieu (1930-2002), que se instrumentalizará a abordagem crítica a Piketty. Dentro deste universo teórico, os conceitos de capital, habitus e campo serão fundamentais - e melhor elucidados na segunda seção deste artigo.

Importante deixar claro, desde já, que esta crítica/diálogo não visa refutar o trabalho de Thomas Piketty; nem mesmo desqualificá-lo. Reconhecese o grande esforço intelectual que o economista francês realiza para lidar com temas socioeconômicos, além das importantes contribuições que ele trouxe para o debate político da atualidade. Desta forma, o objetivo deste artigo é

3 Em vias de evitar confusões, deve-se ter clareza conceitual ao se referir a um determinismo econômico, o qual se refere a uma visão estreita da sociedade na qual o elemento econômico é reificado; esta posição é tomada por Piketty e aqui criticada através da teoria bourdieana. Por outro lado, é possível falar de uma determinação econômica, i.e., a capacidade que as questões econômicas têm de condicionar a sociedade através de mecanismos de reprodução social; este ponto é tomado tanto por Piketty quanto por Bourdieu, assim como pelo autor.

Caderno Eletrônico de Ciências Sociais, Vitória, v. 9, n. 1, pp. 92-111, 2021. 
mostrar que a noção tradicional de capital - capital econômico - é insuficiente para abordar fenômenos sociais, neste caso, a desigualdade. Contestando o determinismo econômico, argumentar-se-á que os elementos simbólicos são essenciais para a constituição da desigualdade, no que há uma série de mecanismos para além da economia que levam a esta condição. A hipótese, assim, é que a desigualdade é fruto da combinação de diferentes capitais que circulam entre campos sociais e que se articulam através das relações de poder, de modo a seguir o arcabouço teórico bourdieano.

Para levar a cabo tal empreendimento, será dedicada uma primeira seção para analisar a obra de Piketty - assim como as críticas a ele realizadas; estas que por vezes trazerem bons argumentos, mas não conseguem sair do círculo materialista e do respectivo determinismo econômico. A segunda seção será responsável por fazer o levantamento de conceitos centrais na obra de Bourdieu para assim, na terceira seção, tecer a crítica dirigida por este artigo, o qual propõe "Os capitais no Século XXI" como uma melhor forma de se compreender o fenômeno da desigualdade com o qual Piketty se preocupa.

\section{A desigualdade analisada sob o determinismo econômico: Piketty e seus críticos}

Nesta seção será analisada a obra de Piketty com ênfase no Capital no Século XXI através das partes de seu livro - são quatro. Será dado maior enfoque à terceira parte, tendo em vista que esta é a que trata centralmente sobre a desigualdade. De modo complementar, se articulará tais pontos com a nova produção do economista, Capital e Ideologia. Após, serão observadas algumas críticas dirigidas ao trabalho de Thomas Piketty por parte de importantes intelectuais.

A primeira e a segunda parte 4 do livro "O Capital no Século XXI" dedicamse a estruturar 0 vasto material coletado e produzido por Thomas Piketty e sua equipe ao longo de quinze anos de estudo. Com uma visão mais atenta ao crescimento do que ao desenvolvimento econômico, o economista francês traz na primeira parte a relação entre estoque de capital e renda, diferenciando a estrutura destas duas variáveis nos países desenvolvidos e nos países subdesenvolvidos; mostra, inclusive, alguns mecanismos que perpetuam e aumentam a disparidade econômico entre o centro e a periferia do mundo. Um dos exemplos é o caso da mobilidade de capitais através de investimentos externos que remetem os lucros aos países desenvolvidos. São demonstrados conceitos e fórmulas que tratam da circulação do capital e da renda em âmbito

\footnotetext{
4 "Renda e capital" e "A dinâmica da relação renda/capital", respectivamente.
} 
internacional demonstrando que a desigualdade, para além de interna à sociedade, é presente também na relação entre os países.

$\mathrm{Na}$ segunda parte, ainda em diálogo com a primeira, Piketty (2014) mostra como os países precursores do capitalismo conseguiram mudar sua estrutura de capital, que o formato agrícola deu lugar ao capital financeiro, imobiliário e industrial, ainda que mantivesse a relação estoque de capital/renda mais ou menos da mesma forma. O capitalismo tardio ao redor do mundo levou países periféricos a absorverem a estrutura agrário-exportadora em vias de possibilitar a expansão industrial e financeira do centro global (WALLERSTEIN, 1974) em uma relação assimétrica interestatal que permanece até então. Para além disso, ainda na segunda parte do livro, é fundamental o ponto observado sobre a tendência de crescimento do capital privado em detrimento do capital público, questão ligada ao mercado financeiro e aos processos de privatização da esfera pública. Nesse sentido, é trazida a questão da tecnologia e do aprimoramento do trabalho humano, o qual passou a requerer maior especificidade e conhecimento técnico.

A sequência lógica às duas partes supracitadas se dá na terceira e mais importante parte do livro - por se tratar do problema central abordado pela obra -, "a estrutura das desigualdades" (PIKETTY, 2014, p.231). Já no início da seção é colocado por Piketty (2014, p.233) que a redução na desigualdade, vislumbrada ao longo do Século XX, é fruto tanto das políticas públicas que visavam o bem-estar social quanto das duas guerras mundiais que ocorreram eventos interligados. Contudo, a partir da década de 70 há um constante aumento na desigualdade. Logo, três termos são expostos para explicar o porquê disso: i) a desigualdade da renda do trabalho; ii) a desigualdade da propriedade de capital e das rendas que dela resultam; e iii) a intersecção entre as duas primeiras. Essa questão da evolução dos regimes de desigualdade ao longo da história recebe maior atenção pelo economista francês em sua mais recente obra (PIKETTY, 2020).

Sobre a concentração de renda, o gráfico 1 mostra o quanto os $10 \%$ mais ricos dos países/regiões demonstrados detém da riqueza total. 
Gráfico 1: Fatia de riqueza dos $10 \%$ mais ricos (2018)

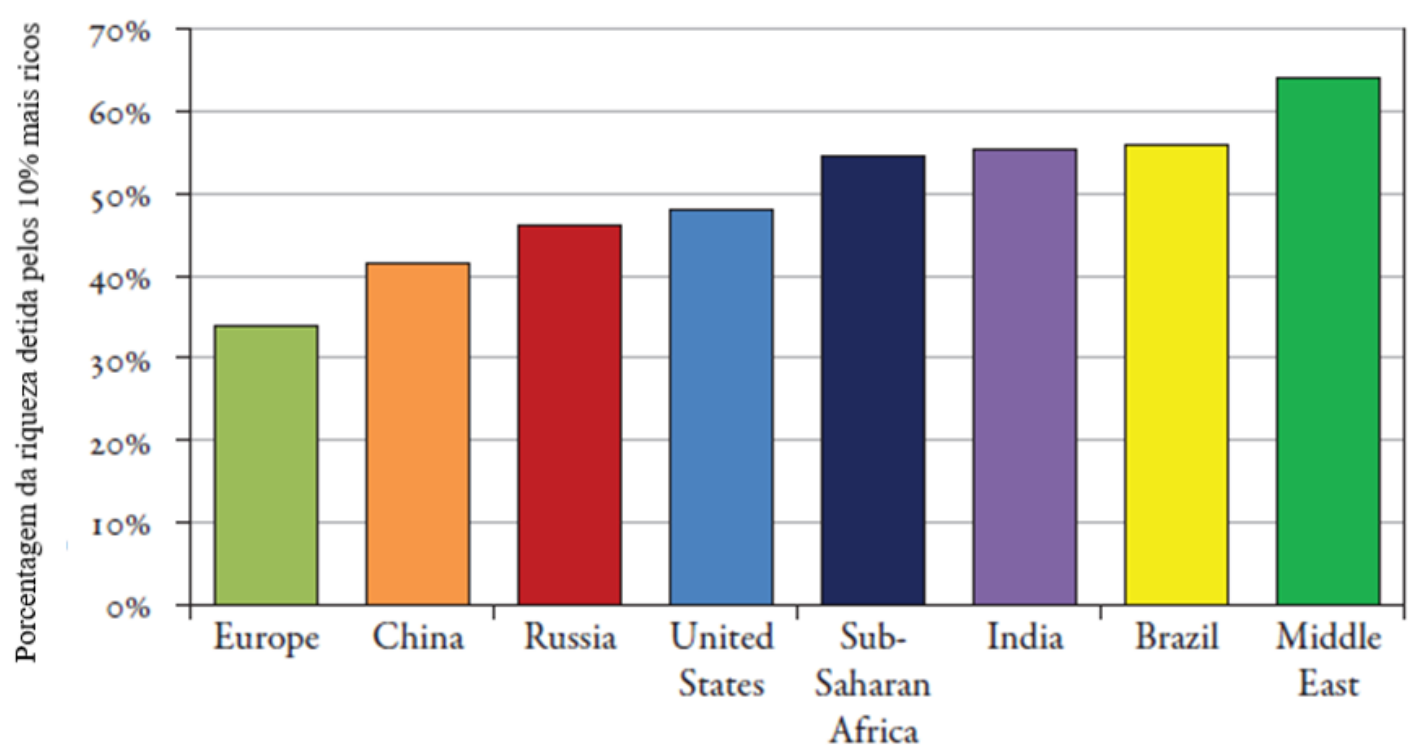

Fonte: Extraído de Piketty (2020, p. 23)

Mais do que uma questão meramente quantitativa, o grande ponto apontado por Piketty (2014) é que a concentração de capital é maior do que a da renda/trabalho, o que coloca a questão da desigualdade em um ciclo vicioso se não regulamentada - questão com a qual ele se ocupará na quarta parte do livro. Logo, o cerne da desigualdade está, segundo Piketty (2014), na disparidade de renda lograda através do capital, e não na renda conquistada a partir do trabalho. Isso traz questões problemáticas para a vida em sociedade, como a dificuldade de mobilidade socioeconômica e o respectivo fato de que para ser rico é muito mais importante já ter riquezas do que trabalhar para isso - questão esta que será melhor refletida no diálogo com Pierre Bourdieu .

Chega-se à quarta parte da obra de Piketty (2014), na qual é sugerida a regulamentação governamental em algumas esferas para impedir que a desigualdade cresça geometricamente. Observa-se como um pressuposto central no argumento do economista francês a figura do Estado enquanto um importante regulador da economia, pois há uma descrença na autorregularão do mercado ou na maior igualdade a partir do desenvolvimento econômico. Com isso, Piketty (2014) busca refutar a tese de Simon Kuznets - conhecida como a Curva de Kuznets -, a qual defende que, ao longo do tempo, o desenvolvimento traz a redução da desigualdade. Nisso vem as duas principais propostas política feitas por Thomas Piketty: i) reforma fiscal que contemple uma tributação progressiva e ii) taxação sobre heranças e grandes fortunas.

O próprio primeiro capítulo desta quarta parte possui o título "Um Estado social para o século XXI" (PIKETTY, 2014, p. 459). Além das reformas necessárias para e pelo Estado segundo Piketty, é abordada ainda a questão da 
dívida pública - que se insere no escopo da privatização da esfera pública, questão supracitada; algo fundamental para o debate tanto em países desenvolvidos quanto em desenvolvimento. $O$ caso brasileiro é emblemático em relação à dívida enquanto fator-chave da desigualdade, por exemplo. Logo, o economista francês realiza um resgate histórico no qual analisa o papel do Estado social como financiador do bem-estar social e provedor de direitos básicos como saúde, educação, previdência e segurança. Traz, assim, a importância da tributação na promoção de justiça social, conforme é possível observar no seguinte trecho: (PIKETTY, 2014, p. 465):

A alta da participação da arrecadação das riquezas produzidas permitiu ao poder público cuidar de missões sociais cada vez maiores, representando entre um quarto e um terço da renda nacional dependendo do país. Essas missões podem ser divididas, num primeiro momento, em duas categorias de tamanho comparável. Trata-se, de um lado, das despesas públicas de educação e saúde e, de outro, das rendas de substituição e de transferência.

Compreende-se, então, que a privatização da renda nacional, principalmente quando não tributado, corre na mão inversa de um Estado que consegue proporcionar justiça social para seus cidadãos. A concentração de riqueza gera um efeito nocivo em políticas públicas que atuem nas duas categorias citadas pelo economista, ou seja, i) investimentos como saúde e educação ii) e políticas de substituição e/ou transferência de renda. Contudo, apenas o Estado nacional não consegue mais equacionar a questão da desigualdade, tendo em vista a internacionalização da economia e a existência de paraísos fiscais. Desta forma, o único modo de contornar tal cenário seria (PIKETTY, 2014, p.501): "[...] um imposto mundial e progressivo sobre o capital, acompanhado de uma grande transparência financeira internacional". Essas são as questões fundamentais do Capital no Século XXI, leitura obrigatória para quem pretende discutir as desigualdades na contemporaneidade.

Todavia, apesar da magnitude e da qualidade do livro, uma série de críticas - algumas de conhecidos intelectuais - foram dirigidas à obra de Thomas Piketty (2014). Em "Notas críticas sobre O Capital no século XXI de Thomas Piketty" Rosa Marques e Marcel Leite (2016) sintetizam algumas das críticas dirigidas ao economista francês em relação ao conteúdo do livro aludido no título. Ao trazer nomes como o britânico David Harvey, o francês Michel Husson e o grego Yanis Varoufakis, os autores colocam a crítica dentro do arcabouço teórico do marxismo, ainda que reconhecendo a existência de demais trabalhos críticos a Piketty (MARQUES; LEITE, 2016, p. 686). A intenção aqui não é se desdobrar sobre as críticas, mas sim, mostrar como tais críticas incorrem em sérios problemas ao tratar a questão da desigualdade, pois tais trabalhos

Caderno Eletrônico de Ciências Sociais, Vitória, v. 9, n. 1, pp. 92-111, 2021. 
atacam Piketty dentro do mesmo ciclo economicista; não reconhecem que há outros elementos que contribuem na criação do fenômeno da desigualdade. Não só na vertente marxista da crítica isso ocorre: liberais que criticam Piketty (2014) também se envolvem em um ciclo puramente economicista, como é o caso de Jean-Philippe Delsol, Nicolas Lecaussin e Emmanuel Martin em "AntiPiketty: Capital for the 21st Century" (2017)

O geógrafo David Harvey (2014) tece sua crítica em relação à ausência de explicação sobre a inversão da Curva de Kuznets realizada por Thomas Piketty, na qual o francês coloca que o capitalismo tende a aumentar a desigualdade entre o capital e o trabalho. Tal questão se assemelha a um dos problemas levantados por Varoufakis (2014). O ex-ministro grego traz as mais ácidas críticas à Piketty (2014); argumenta em última instância que (VAROUFAKIS, 2014, p.32): "Capital in the Twenty-First Century has been hailed as a book to turn the tide of inequality; a treatise that will blow fresh winds into egalitarianism sails. I very much fear it will do the opposite" ${ }^{\prime \prime}$. Tal colocação tem como base a crítica da visão de Piketty (2014) em relação a uma potencial "lei natural" do capitalismo em aumentar progressivamente as assimetrias de riqueza, fruto de algumas outras reduções conceituais realizadas pelo economista francês como na questão de renda e capital (VAROUFAKIS, 2014; HUSSON, 2014; MARQUES; LEITE, 2016).

Se David Harvey (2014) e Yanis Varoufakis (2014) criticam Piketty (2014) neste sentido, deve-se ter em vista que tal discussão é antiga e remete ainda a Karl Marx, como bem coloca Michel Heinrich (2004). No seio do marxismo há uma divisão entre aqueles que acreditam em algumas leis de ferro do capitalismo e outros que acham dificilmente comprovar uma tendência contínua (HEINRICH, 2004). O economista francês, apesar de não ser um marxista, adota uma destas leis de ferro em vias de robustecer o argumento teórico em relação aos dados coletados. Pode-se dizer que há uma tendência em desigualdades e assimetrias se perpetuarem no sistema capitalista, mas por motivos além da pura concentração de renda e riqueza - questão que será central no decorrer deste artigo.

A crítica de Michel Husson (2014) trilha caminhos semelhantes ao que foi supracitado. A indistinção entre renda e capital leva Piketty (2014) a não conseguir fazer uma estimativa de longo prazo - o que é sua intenção - pela insuficiência em diferenciar capital produtivo de capital rentista (HUSSON, 2014). Essa é uma boa crítica no que se dirige também a questão dos mecanismos de desigualdade na distribuição da riqueza, trabalhada por Piketty

\footnotetext{
5 "Capital no Século XXI foi recebido como um livro para virar a maré da desigualdade; um tratado que iria trazer ventos frescos ao velejar do igualitarismo. Eu realmente temo que 0 livro fará o oposto". Traduzido pelo autor.
} 
(2014) enquanto a "terceira lei do capitalismo". O economista francês se justifica (PIKETTY, 2014, p. 53):

\begin{abstract}
Para simplificar, usaremos as palavras "capital", "riqueza" e "patrimônio" de forma intercambiável, como se fossem sinônimos perfeitos. Segundo algumas definições, deveríamos reservar o uso da palavra "capital" para designar o estoque de riqueza acumulado pelo homem (edificações, máquinas, equipamentos etc.), excluindo a terra e os recursos naturais, que a espécie humana herdou diretamente, sem ter de acumulá-los. Desse modo, a terra seria um componente da riqueza, do patrimônio, e não do capital. A dificuldade é que nem sempre é possível separar o valor das edificações do valor dos terrenos sobre os quais são construídas. [...] Os mesmos problemas valem para os recursos naturais - petróleo, gás, os metais conhecidos como "terras-raras" etc. -, uma vez que é muito complexo distinguir seu valor puro dos investimentos realizados para descobri-los e explorá-los. Assim, incluiremos todas essas formas de riqueza na definição de capital [...] Segundo outras definições, deveríamos reservar a palavra "capital" para nos referir aos componentes da riqueza usados diretamente no processo de produção [...] Todas as formas de capital sempre desempenharam um papel duplo, em parte como reserva de valor, em parte como fator de produção. Pareceu-nos, portanto, mais simples não impor distinções rígidas entre os conceitos de riqueza e de capital.
\end{abstract}

O grande ponto aqui, contudo, é demonstrar como as críticas possíveis ao trabalho de Thomas Piketty (2014) circulam no economicismo, no que carecem de outras referências epistemológicas. O mesmo ocorre quando se toca na crítica a matriz teórica da influência marxista ao liberalismo. Em uma obra que se propõe a inverter os pressupostos de Piketty (2014) e as respectivas sugestões para amenizar os efeitos da desigualdade, Jean-Philippe Delsol (2017) e demais autores trazem em Anti-Piketty uma visão liberal sobre as questões abordadas por Thomas Piketty. Importante frisar que o próprio Piketty não é nenhum marxista, julgado inclusive como um "neoclassicista vulgar" por Yanis Varoufakis (2014, p.28). Ainda assim, o economista francês sofre duras críticas de ambos os lados. Entretanto, deve-se criticar a todos, tanto ao criticado quanto aos críticos, no que argumenta-se aqui ser o próprio Piketty o único desses que ainda se propõe a trazer alguma questão associada a reprodução social enquanto mecanismo de sua "terceira lei fundamental" (PIKETTY, 2014) ou enquanto ideologia (PIKETTY, 2020). A partir daqui se realizarão críticas a partir da teoria bourdieuana ao economicismo com o qual a desigualdade é tratada conforme o diálogo entre economistas.

\title{
Capital, campo e habitus: componentes da sociologia econômica de Pierre Bourdieu
}

Caderno Eletrônico de Ciências Sociais, Vitória, v. 9, n. 1, pp. 92-111, 2021. 
Conforme descrito na introdução, esta seção será responsável pela reconstrução da obra de Bourdieu, com ênfase nos pontos que possibilitam uma sociologia econômica em vias de lidar com o objeto deste artigo. Ao elucidar alguns pontos da teoria bourdieana, será possível encaminhar o que se propõe enquanto capitais no século XXI, projeto viável através do diálogo crítico entre Pierre Bourdieu e Thomas Piketty - este será o foco da próxima seção.

Com formação sociológica e filosófica, Bourdieu traz importantes conceitos para a compreensão da desigualdade. Ao colocar enquanto centro de suas análises a realidade da França e de suas colônias, o sociólogo consegue criar um arcabouço teórico aplicável a diversos contextos geográficos ainda hoje. Centrais para a proposta deste artigo são as noções de capitais e habitus, constructos que integram aquilo que se conhece por "Teoria dos Campos" de Bourdieu. Ao se apreender essas noções, construir-se-á aqui um argumento sobre como as categorias de Bourdieu podem ser aplicadas de modo a suprir os déficits da proposta de Piketty (2014).

Em A distinção: crítica social do julgamento, Bourdieu (2007a) escancara a divisão de indivíduos em diferentes esferas sociais, no que mostra como determinados comportamentos e conhecimentos são legitimados em detrimento de outros. Para além da herança marxista e do materialismo dialético que privilegia a dimensão econômica e suas contradições, Bourdieu (2007a) atribui a centralidade da noção de capital à formulação do capital simbólico, do qual se derivam outros três tipos de capitais: o social, o cultural e o econômico. Isso pois, todos os capitais, no que inclui sua concepção econômica, dependem de uma crença coletiva quanto ao seu valor (BOURDIEU, 2004); tem-se o capital enquanto representação social - de certo modo, isto remete ao triplo fenômeno de alienação, fetichismo e reificação do capital conforme trabalhado por Marx (1985). Ainda, há uma série de capitais que se derivam dos supracitados, enquadrados em diferentes situações conforme o campo em questão.

Essa múltipla capacidade de conversão dos capitais parte da natureza histórica-contingencial com a qual Bourdieu instrumentaliza seu arcabouço teórico (STEINMETZ, 2011); pode-se tomar do próprio Bourdieu (1995, p. 116) que: "Il ne faut jamais prendre les concepts de I'histoire (ou de la sociologie) qu'avec des pincettes historiques [...] il faut, pour historiciser vraiment les concepts, faire une généalogie socio-historique des différents champs sémantiques" $^{\prime 6}$. Na obra de Pierre Bourdieu há uma quebra com qualquer reivindicação transcendente quanto aos conceitos, de modo a assentar sua teoria em uma crítica ao estruturalismo a-histórico e fundamentar, assim,

\footnotetext{
6 "Devemos tomar os conceitos da história e da sociologia com pinças históricas [...] precisamos, para de fato historicizar os conceitos, fazer uma genealogia sócio-histórica dos diferentes campos semânticos". Traduzido pelo autor.
}

Caderno Eletrônico de Ciências Sociais, Vitória, v. 9, n. 1, pp. 92-111, 2021. 
aquilo que pode ser compreendido como estruturalismo genético, uma posição ontológica na qual as estruturas sociais possuem gêneses e características diferentes conforme seus contextos. Dessa forma, o modo de produção capitalista, enquanto fenômeno espaço-temporal, fomenta a emergência dos capitais; não apenas o econômico - conforme trabalhado em Marx (1985) e apropriada por Piketty $(2014 ; 2020)$ - mas, principalmente, o simbólico, do qual aquele se deriva.

É fundamental também a concepção epistemológica de superar o dualismo entre subjetivismo e objetivismo em vias de compreender a realidade social como uma intersecção de elementos materiais e simbólicos, de modo explicitado por Bourdieu (2007b) em A economia das trocas simbólicas, no que pode ser considerado um relacionalismo metodológico sistemático (WACQUANT, 2013). A questão chave é que os capitais se referem a recursos de poder que atuam através de relações no campo social. A concepção de poder presente em Pierre Bourdieu possui semelhanças com a proposta por Michel Foucault; apesar das suas diferenças, compartilham o elemento central de que o poder é possível apenas em uma rede de relações, não sendo o recurso ao poder, em si, uma capacidade, mas apenas uma espécie de "vontade de potência" - para empregar o léxico nietzschiano. Por questões de escopo, tais relações entre autores não serão aprofundadas.

Na teoria bourdieana, às dinâmicas específicas de poder e distinção na sociedade capitalista é dado o nome de campo, local em que os capitais são gerados através de disputas. Os campos são estruturados através da quantidade e da qualidade dos capitais dispostos pelos indivíduos e/ou grupos que o compõem; essa estruturação determinará a posição social dos agentes no interior de cada campo (BOURDIEU, 2007a; 2009). Para exemplificar o constructo do campo, pode-se pegar o campo científico. Aqueles que dispõem de um alto capital cultural serão considerados intelectuais de prestígio; torna-se legítimo aquilo que eles disserem no interior de tal campo do saber. Investe-se, ainda, o intelectual de capital simbólico, materializado na figura do diploma, por exemplo. Aqueles dotados da combinação de capitais necessária para assumir o topo de um determinado campo serão os responsáveis por ditar as regras, criar as crenças e os ritos daquele campo, elementos que funcionam enquanto forma de manter os capitais nas mãos desta mesma classe e de evitar grandes mobilidades de capital.

Assim, o sistema capitalista proporciona uma assimetria na distribuição de recursos (compreendidos amplamente), pois nos diferentes campos, aqueles agentes que já detém capitais tendem a manter e a ampliar estes através das conversões demandadas pelo campo em questão. No que será melhor abordado na próxima seção, percebe-se uma manutenção da ordem vigente através da

Caderno Eletrônico de Ciências Sociais, Vitória, v. 9, n. 1, pp. 92-111, 2021. 
reprodução social - a qual favorece os já favorecidos. O papel do Estado nestas disputas pela conversão de capitais é fundamental, pois o mercado não é apenas controlado pelo Estado como, também, construído por este, de modo que ele atua "favorecendo mais ou menos uma ou outra categoria social" (BOURDIEU, 2001, p.125).

Não cabe aqui uma divagação sobre a sociologia histórica que tome a formação do Estado moderno como seu centro, algo já amplamente discutido e abordado na academia. Em vias de incorporar a fundamentação de Pierre Bourdieu sobre tal ente, refere-se apenas ao importante papel que possui obras como a de Charles Tilly (1996) na quebra com a noção contratualista do Estado enquanto necessidade natural - ou algo do tipo. Crítica também presente em Marx (2013), o Estado não pode ser encarado enquanto entidade neutra, desprovida dos próprios interesses e tendências. Sua própria formação se deu através da coerção tributária e militar (TILLY, 1996); sua manutenção se faz a partir tanto da violência física (WEBER, 2014) quanto da simbólica (BOURDIEU, 2014b) $)^{7}$.

De modo análogo ao que ocorre com a primazia do simbólico no que tange os capitais, Bourdieu (2014b, p. 30), de certa forma, inverte a clássica premissa weberiana ao apontar que "o monopólio da violência simbólica é a condição da posse do exercício do monopólio da própria violência física". É um avanço político-sociológico aquilo que Pierre Bourdieu (2014b, p.155), inspirado em Gaston Bachelard, propõe enquanto um enfoque genético do Estado. Nesse, emerge um materialismo do simbólico no qual o Estado é tomado enquanto fato conquistado e construído, não naturalizado. Se já apontada a inspiração marxiana de Bourdieu no que concerne o Estado, o sociólogo francês vai além ao problematizar não apenas o favorecimento deste ente em relação a determinados agentes, mas sim, ao questionar o próprio ser do Estado. Ainda, em Jung (2019) percebe-se a importância da contribuição de Bourdieu para se pensar o Estado tanto no âmbito doméstico quanto no internacional, no que tange as relações de poder que perpassam o relacionamento interestatal.

Constituídas as noções de capital e campo em Bourdieu, parte-se ao terceiro ponto da tríade aqui proposta enquanto fundamental para a

\footnotetext{
7 Deve-se ter em vista que a leitura da formação do Estado, aqui não aprofundada por questões de escopo, possui distinções ao redor do globo. O que se tem enquanto "formação do Estado nação" é, em outras palavras, a formação do Estado europeu, de modo que tal compreensão se universalizou. Os empreendimentos coloniais e as lutas por autodeterminação suscitam outros modelos de Estado que se desdobraram pelo mundo, de modo a posicionar, inicialmente, assimetrias entre um centro e uma periferia global. Tais questões são canonicamente trabalhadas na historiografia de Fernand Braudel, no que compreende as contribuições intelectuais da École des Annales; do mesmo modo, conforme citado aqui, Immanuel Wallerstein (1974) fornece uma base para se pensar em tais questões.
}

Caderno Eletrônico de Ciências Sociais, Vitória, v. 9, n. 1, pp. 92-111, 2021. 
compreensão de uma sociológica econômica neste autor: o conceito de habitus. Com origem na hexis aristotélica ${ }^{8}$, a incorporação do habitus ao arcabouço teórico remonta em Bourdieu (2009) uma ruptura com o modelo estruturalista que predominava na sociologia francesa. 0 indivíduo abandona o papel passivo frente à estrutura, passa de mero "suporte de estruturas investidas com o poder" (BOURDIEU, 2007b, p. 296) ao status de agente, i.e. dotado da capacidade de ação para além dos meros condicionamentos estruturais.

Se os capitais são os recursos de poder que se efetivam através das relações realizadas dentro de um determinado campo, o habitus é a incorporação das práticas sociais determinadas pela estruturação dos campos, é o "o funcionamento sistemático do corpo socializado" (BOURDIEU, 2009, p. 62). O habitus é responsável pela formação de gostos, hábitos, costumes e, no geral, pela constituição da identidade do indivíduo em relação à sociedade. Ainda, segundo Wacquant (2013, p.88) o habitus é como: "[...] experimentamos internamente e construímos ativamente o mundo vivido". Desta forma, o habitus atua enquanto uma espécie de interiorização sociológica no agente.

Nesse sentido, o habitus é uma mediação entre as estruturas sociais e a prática do agente, de modo que aquelas se reproduzem através dessas, na ação do sujeito o qual incorporou em si sua posição de classe (BOURDIEU, 2007b). Há uma afinidade entre determinados agentes através de um habitus compartilhado, de modo que, em meio aos antagonismos e às disputas que ocorrem dentro dos distintos campos, alianças de interesses emergem a partir da convergência destes habitus (BOURDIEU, 2001, p.128). Em Bourdieu (2014b, p.61) encontra-se que o Estado "reforça um ponto de vista entre outros sobre o mundo social, que é o lugar de luta entre os pontos de vista. Ele diz acerca desse ponto de vista que é o ponto de vista certo, o ponto de vista dos pontos de vista". Desse modo, alguns habitus tornam-se mais legítimos do que outros, ou, pelo menos, mais valorizados, questão esta que é central em Bourdieu (2007a).

Eis o Estado burocrático enquanto banco central do poder simbólico, árbitro de disputas sobre categorias e na certificação de identidades (WACQUANT, 2013, p.89). Compreende-se, enfim, como a teoria dos campos os respectivos conceitos de capitais, campo e habitus são utilizados. Apesar de compreendida em Pierre Bourdieu a "radical contextualidade de seu argumento" (SOUZA, 2006, p.85), na qual tais noções se inserem dentro de um determinado espaço-tempo em que Bourdieu produziu sua teoria (STEINMETZ,

\footnotetext{
8 A noção de hexis, presente na ética aristotélica, poderia ser traduzida por algo como disposição, a qual apontaria a um estado de espírito duradouro do sujeito. Como disposto no corpo do texto, é deste espírito duradouro, absorvido, pelo agente que se forma o habitus.
}

Caderno Eletrônico de Ciências Sociais, Vitória, v. 9, n. 1, pp. 92-111, 2021. 
2011), defende-se a aplicabilidade desses termos para lidar com a questão da desigualdade ainda hoje, centralmente naquilo que este artigo tem enquanto objeto: uma compreensão mais ampla de tal fenômeno do que a evidenciada nos estudos econômicos ${ }^{9}$.

Através de a miséria do mundo (BOURDIEU, 2003) se evidencia a denúncia - politicamente engajada, inclusive - da desigualdade social por parte do intelectual, de modo a transpor críticas para além de seu contexto. Dessa forma, a próxima seção se ocupará da aproximação entre o universo bourdieano e a desigualdade analisada por Piketty $(2014 ; 2020)$, em vias de demonstrar como uma abordagem sociológica desta questão pode enriquecer o exaustivo trabalho realizado pelo economista francês; encaminha-se às estruturas sociais da economia (BOURDIEU, 2001), a uma formulação sociológica econômica.

\section{O diálogo entre Thomas Piketty e Pierre Bourdieu: para além do determinismo econômico}

Ao se ter em vista as reconstruções elaboradas nas duas seções anteriores, parte-se agora ao subtítulo deste artigo: o estabelecimento de um diálogo crítico entre Thomas Piketty e Pierre Bourdieu. Ao atribuir o papel da redução da desigualdade às políticas públicas e medidas regulatórias que consigam amenizar a distância social, Piketty (2014) tem em sua obra uma análise da desigualdade quase que puramente a partir do viés econômico. Um gancho interessante, contudo, é a questão da herança, amplamente trabalhada pelo autor. Quando na quarta e última parte de seu livro o economista propõe que a taxação de herança deve ser um dos principais mecanismos de redistribuição de renda, há um indício do papel da transmissão dos capitais hereditários conforme tratado por Pierre Bourdieu (2007a). A incorporação do habitus e a transformação dos tipos de capitais trabalhada pelo sociólogo francês é um bom ponto para se explorar uma possível aproximação e respectiva crítica à Piketty (2014).

Ainda que referente ao caso brasileiro, pode-se remeter aqui ao que Jessé de Souza (2006) argumenta sobre a falibilidade da crença no progresso econômico - ou hipereconomisicmo - enquanto fenômeno capaz de resolver conflitos e contradições de uma sociedade desigual. Há uma elasticidade semântica do mundo social (BOURDIEU, 2009) que possibilita a incorporação

\footnotetext{
${ }^{9}$ Seria ingênuo tomar Bourdieu a-críticamente, em vias de pensar que tal pensador possui todas as ferramentas necessárias à compreensão da desigualdade, o que tornaria sua teoria universal e sincrônica. Há uma série de críticas possíveis à teoria bourdieana, a começar pela própria obra do aqui citado Jessé de Souza; o que é pretende aqui, contudo, é se valer da contribuição de Bourdieu no intuito de estabelecer um diálogo crítico com Piketty. Este grande (e rico) debate teórico das ciências sociais, na qual se pese as deficiências e virtudes da teoria bourdieana não adentra no escopo deste artigo.
}

Caderno Eletrônico de Ciências Sociais, Vitória, v. 9, n. 1, pp. 92-111, 2021. 
dos elementos materiais e simbólicos na análise realizada por Piketty (2014). Propõe-se aqui uma apropriação da análise empírica realizada por Piketty - a despeito das críticas aludidas na seção anterior - para que, com as categorias de Pierre Bourdieu, seja possível ampliar qualitativamente o estudo. Assim, o que então se tem como capital na obra de Piketty (2014) se lê aqui enquanto capital econômico; a concentração deste em alguns agentes é causa e consequência de como os demais capitais circulam e se convertem dentro do grande campo social.

Desse modo, é necessário considerar a formação de uma dialética objetividade/subjetividade de modo a compor a materialização de um determinado imaginário social. O conceito de alquimia sociosimbólica (BOURDIEU, 2009) refere-se ao fenômeno de como um constructo mental converte-se em realidade social de modo a afetar as próprias estruturas sociais a partir da ação de determinados agentes. O que se trabalhou enquanto as funções do Estado - na seção anterior - é um bom apontamento para se compreender como essa junção das dimensões simbólica e material ocorre de forma a afetar o modo com o qual os capitais circulam e se convertem nos diferentes campos que estruturam a sociedade (BOURDIEU, 2001). A teoria bourdieana abre espaço para mudanças dentro do campo social; contudo, tais mudanças tendem a ser dirigidas por uma aliança de classes dominantes, detentoras de capitais, legitimadas pelos Estado, em uma articulação que se desdobra através da manipulação simbólica no intuito de manter o status quo com as estratégias de reprodução.

A necessidade de uma regulamentação que consiga equalizar as assimetrias entre a concentração de capital e a renda/trabalho é um dos prognósticos estabelecidos por Piketty (2014); o Estado emerge como o agente responsável por tal regulamentação. O problema ergue-se a partir do momento no qual se compreende a formação de tal ente e a sua respectiva função dupla: i) a de criar as condições de sua autolegitimação (BOURDIEU, 2014b) e ii) a de manter a reprodução social que privilegia a classe dominante (BOURDIEU, 2007b). O efeito degradante que o acúmulo de riqueza na mão de poucos gera é a insuficiência de gerar políticas direcionadas à compensação daqueles que se veem afastados da obtenção do espólio dos capitais. Aqui já se aponta uma primeira questão às considerações finais, a saber, a reflexão sobre qual ator pode executar a função de regulador da circulação dos capitais de modo a evitar a crescente desigualdade. Percebe-se a insuficiência do Estado - conivente e artífice da própria manutenção de assimetrias; ao mesmo tempo, defender uma discursividade pró-mercado, ou que argumente algo em torno da autorregulação e da racionalidade dos agentes econômicos, recai em uma série de problemas com as quais o próprio Bourdieu já lidou.

Caderno Eletrônico de Ciências Sociais, Vitória, v. 9, n. 1, pp. 92-111, 2021. 
A despeito de divergências já exploradas, um ponto de convergência entre Piketty e Bourdieu se observa na visão compartilhada sobre a tendência de reprodução que a sociedade capitalista comporta. O capítulo 11 de Piketty (2014), assim como a primeira parte do Capital e Ideologia (PIKETTY, 2020), mostra como a detenção de capital econômico proporciona uma perpetuação de riqueza através das relações familiares e, mais especificamente, da herança. Os conhecidos trabalhos de Bourdieu (1982) sobre a educação enquanto espaço de reprodução social se encontram com os dados levantados por Piketty (2014; 2020) sobre o mesmo tempo de modo a formular o gráfico seguinte.

Gráfico 2 - Relação entre acesso à educação superior e renda familiar (2014)

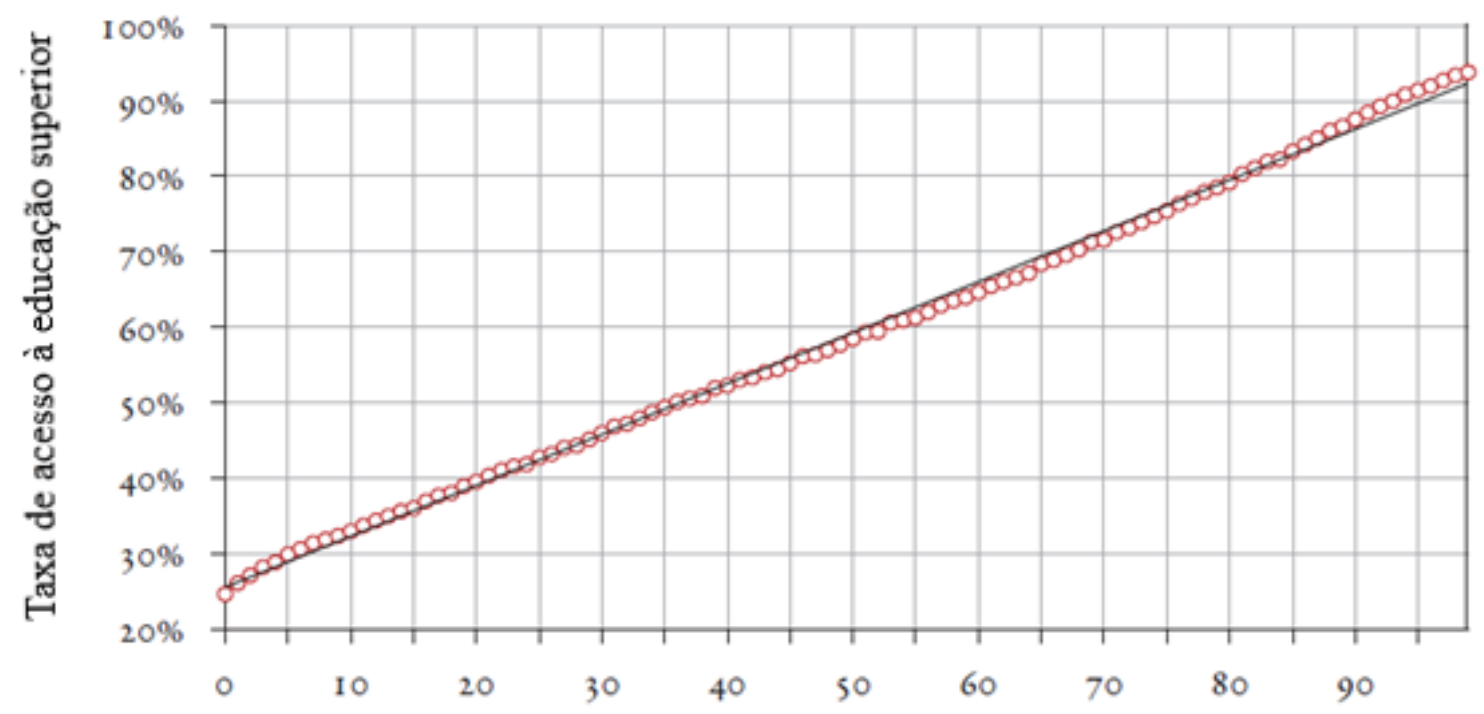

Percentil da renda familiar

Fonte: Extraído de Piketty (2020, p. 35).

Trata-se daquilo que Bourdieu (2007a, p. 122) denomina de estratégias de reprodução, nas quais as famílias conservam ou aumentam seu patrimônio em vias de manter ou melhorar sua posição nos distintos campos. Percebe-se, quando comparados os gráficos 1 e 2, que este último apresenta uma melhor possibilidade para a aproximação entre os levantamentos feitos por Piketty (2014; 2020) e as contribuições de Bourdieu; há uma institucionalização da desigualdade em diversas esferas.

Nesse sentido, se retoma a proposição de Marx (2013) sobre ser o Estado um espaço de manutenção da dominação burguesa. Em Hegel (2005) o Estado aparece enquanto manifestação do espírito objetivado na esfera da eticidade de modo a promover uma vida ética entre os indivíduos; a partir desta leitura elaborou-se correntes de pensamento que viam na figura do Estado um espaço para suprir as deficiências da sociedade civil. Contudo, este sistema de

Caderno Eletrônico de Ciências Sociais, Vitória, v. 9, n. 1, pp. 92-111, 2021. 
carências - para manter o léxico hegeliano - acaba por danificar a construção de um todo ético; é a partir daqui que Marx (2013) dirige sua crítica a Hegel.

Ao retomar o vocabulário bourdieano, entende-se a assimilação que a classe dominante faz do Estado através de uma conjugação material-simbólica na conversão de capitais de modo a efetivar na carência o próprio epicentro da sociedade capitalista - e a partir daqui os discursos meritocráticos ganham força em vias de legitimar discrepâncias sociais (BOURDIEU, 2007a). A ideia de uma constituição que venha a regular as práticas humanas em um determinado cânone ético (HEGEL, 2005) acaba por se desvelar em dominação simbólica, transmitida através da obra de Bourdieu (2007b) enquanto controle jurídicosocial; eis o sistema de ensino enquanto um tipo-ideal de instituição que reproduz esta lógica (BOURDIEU, 2014a). Sobre esta questão no tempo presente, Piketty (2020, p. 542) aponta:

[...] even when college is free or nearly free and most of the cost is borne by the government, true equality access to higher education is nevertheless not guaranteed. Students from privileged backgrounds are often better placed to enter more promising courses of study, thanks both to their family heritage and to prior access to better schools and high schools. ${ }^{10}$

De modo já aludido, as estratégias da reprodução social perpassam por uma série de instituições - como a educação, conforme supracitado - em vias de manter uma certa margem dentro da qual as mudanças de classe são possíveis. O epicentro desta questão remete à instituição da herança em um formato que tanto Thomas Piketty quando Pierre Bourdieu concordarão ser esta o vetor da manutenção de tais margens. Conforme percebido com a citação anterior de Piketty, não é possível remediar a desigualdade no acesso à educação - a qual por sua vez leva a um ciclo de perpetuação da desigualdade - apenas com ações afirmativas ou financiamento público de acesso ao ensino. Isso pois há toda uma gama de elementos simbólicos, que perpassa pela obtenção de distintos capitais, que impedem o acesso e o desenvolvimento de classes que sempre se viram excluídas de certos meios.

O economista ainda aponta como o recrudescimento na desigualdade generalizada pós-1970 é paralelo ao aumento no fluxo de heranças (PIKETTY, 2014, pp.414-415). Assim, se tem toda uma circularidade de capitais que formulam habitus que serão mais ou menos valorizados dentro do sistema de

10 "[...] mesmo quando a universidade é gratuita ou próxima disso - e grande parte dos custos é arcada pelo governo - a equidade real no acesso ao ensino superior não é garantida. Estudantes de realidades privilegiadas são frequentemente melhor colocados para entrar em cursos mais promissores, graças tanto à herança familiar quanto ao acesso anterior às melhores escolas". Traduzido pelo autor.

Caderno Eletrônico de Ciências Sociais, Vitória, v. 9, n. 1, pp. 92-111, 2021. 
ensino, de modo a hierarquizar o interior de uma sala de aula (BOURDIEU, 2014a). Nesse cenário, tende-se a uma naturalização de que certas classes ocuparão certos postos, questão esta que cria um ciclo vicioso numa dialética com tentativas ineficazes - de viés puramente econômico - na tentativa de tornar as fronteiras de movimentação social mais porosas.

Como forma de encaminhar às considerações finais, resgata-se o argumento central da última obra de Thomas Piketty (2020, p.1), o de que a desigualdade tem uma dimensão ideológica na qual uma série de discursos e práticas são articulados em vias de legitimar as assimetrias sociais. Dentro da obra do economista, tal questão é um grande avanço em relação ao Capital no Século XXI - questão esta admitida pelo próprio Piketty (2020, p. ix). Ainda, percebe-se como este argumento abre um espaço ainda maior ao diálogo com a sociologia econômica de Pierre Bourdieu, ao se ter em vista os elementos simbólicos que a dimensão ideológica traz consigo. Enfim, viabiliza-se uma dialética do material a qual, para além do determinismo presente no materialismo dialético, conduz a análise do fenômeno da desigualdade a um arcabouço teórico enriquecido; não mais o capital, mas sim os capitais devem ser pensados no século XXI enquanto forma de superar as aporias de uma sociedade fragmentada e desigual.

\section{Considerações Finais}

A interessante obra de Thomas Piketty (2014), a qual reuniu tanto adeptos quanto críticos, mostra-se insuficiente em termos sociológicos no que tange o direcionamento de seu próprio prognóstico. Através de Pierre Bourdieu é possível expandir a hermenêutica do capital e compreender como a circulação moderno-capitalista deste abarca um arcabouço ampliado, no qual o material e o simbólico estabelecem uma dialética que produz, em sua síntese, uma espécie de materialismo simbólico. Assim, o avanço empírico que a obra de Piketty (2014) representa, ganha riqueza teórica ao se acoplar à dimensão simbólica proposta por Pierre Bourdieu; ao mesmo tempo, isso é possibilitado pela amplitude da teoria bourdieana a qual inclui, inclusive, esforços empíricos.

O trabalho aponta para uma hipótese a qual, com Bourdieu, seria possível pensar em uma readequação do prognóstico de Piketty (2014) no que tange a equalização das assimetrias sociais. Mas é necessário ir ainda além, pois a sociologia econômica bourdieana já evidencia a profundidade do problema da desigualdade de modo a invocar ferramentas teóricas alheias à sua própria capacidade. Por isso retoma-se a crítica de Marx (2013) a Hegel (2005) no intuito de questionar a própria função do Estado enquanto agente regulador, em uma retórica que aponta para as deficiências deste ente burocrático em suprir o sistema de carências alocado na sociedade civil.

Caderno Eletrônico de Ciências Sociais, Vitória, v. 9, n. 1, pp. 92-111, 2021. 
Os desafios percebidos no desenrolar da modernidade, que tem na racionalidade sua vertente epistemológica (HABERMAS, 1990) e que encontra na influência de um filósofo como Hegel (2005) a tentativa de superar as aporias da era moderna através de uma razão especulativa - que em termos políticos concede ao Estado a capacidade de compensar os déficits normativos percebe-se chocada com o insucesso de seu próprio edifício. A agência do indivíduo que, enquanto homo faber, fabrica suas próprias limitações (MARX, 2013), permite a modificação estrutural da sociedade (BOURDIEU, 2009). Contudo, alienado de sua própria capacidade, vê sua capacidade de ação diminuída em prol de um agente regulador superior - o Estado - na esperança de ver suas demandas supridas. $O$ problema emerge quando o aparelho estatal se mostra enquanto extensão da burguesia, mecanismo potencializador e reprodutor das assimetrias de capitais (BOURDIEU, 2007b, 2014b) e, inclusive, como importante agente na reconversão de capitais que permite os deslocamentos verticais dentro dos campos (BOURDIEU, 2001; 2007a), isto é, o acúmulo de capitais.

Desse modo, toda a análise feita por Piketty (2014) em seu diagnóstico e prognóstico que apontam a uma necessidade regulatória economicamente viável, mostra-se entravada pelos próprios princípios normativos que regem as esferas nas quais tal regulação poderia ser efetivada. Assim, o problema do capital - no sentido econômico conforme tratado tanto pelo economista francês quanto por Karl Marx - não pode ser tratado segundo sua própria lógica. É necessária uma reconstrução crítico-social que possibilite uma conversão menos assimétrica de capitais em vias de possibilitar uma redução da acumulação de capital nas mãos de alguns poucos.

Se a partir da ampliação do léxico sobre o capital é possível teorizar o objeto deste artigo para além do determinismo econômico - em vias de ensaiar uma sociologia econômica enquanto aproximação teórica necessária -, resolver o prognóstico de Piketty (2014) demanda ainda além: uma crítica filosófica às aporias normativas da sociedade capitalista contemporânea. Sem conseguir aprofundar tal questão neste trabalho, aponta-se uma agenda de pesquisa que parte das conclusões deste artigo para continuar a investigação sobre o problema da desigualdade.

\section{Referências Bibliográficas}

Caderno Eletrônico de Ciências Sociais, Vitória, v. 9, n. 1, pp. 92-111, 2021. 
BOURDIEU, P. 2007a. A distinção: crítica social do julgamento. São Paulo: Edusp.

BOURDIEU, P. 2007b. A economia das trocas simbólicas. São Paulo: Perspectiva.

BOURIDEU, P. 2003. A miséria do mundo. São Paulo: Vozes.

BOURDIEU, P. 2004. A produção da crença: contribuição para uma economia dos bens simbólicos. São Paulo: Zouk.

BOURDIEU, P.; PASSERON, J. 2014a. A reprodução: elementos para uma teoria do sistema de ensino. Petrópolis: Vozes.

BOURDIEU, P. 2001. As estruturas sociais da economia. Lisboa: Instituto Piaget.

BOURDIEU, P. 2009. O poder simbólico. Rio de Janeiro: Bertrand Brasil.

BOURDIEU, P. 2014b. Sobre o Estado. São Paulo: Companhia das Letras.

BOURDIEU, P. 1995. Sur les rapports entre la sociologie et l'histoire en Allemagne et en France. Actes de la Recherche en Sciences Sociales, v.106107, pp. $108-122$.

BOYER, R. 2013. Le capital au XXIe siècle. Revue de la Régulation, n.14, 2e semestre.

DELSOL, J-P.; LECAUSSIN, N.; MARTIN, E. 2017. Anti-Piketty: Capital for the 21st Century. Washington D.C.: Cato Institute.

FOUCAULT, M. 2018. Microfísica do poder. Rio de Janeiro/São Paulo: Paz \& Terra.

HABERMAS, J. 1990. O discurso filosófico da modernidade. Lisboa: Publicações Dom Quixote.

HARVEY, D. 2014. Reflexões sobre "O capital", de Thomas Piketty. Disponível em: <http://blogdaboitempo.com.br/2014/05/24/harvey-reflexoes-sobre-ocapital-de-thomas-piketty/. 2014 >. Acesso em 30/05/2019.

HEGEL, G. W. F. 2005. Introdução à filosofia do direito. Campinas: Ed.UNICAMP.

HEINRICH, M. 2004. An introduction to the three volumes of Karl Marx's Capital. New York: Monthly Review Press.

HUSSON, M. 2014. Le capital au XXIe siècle. Richesse des données, pauvreté de la théorie. Disponível em: <http://www.contretemps.eu/interventions/capital-xxie-si\%C3\%A8cle- - 
richesse-donn\%C3\%A9es-pauvret\%C3\%A9-th\%C3\%A9ori. 2014>. Acesso em 30/05/2019.

JUNG, J. 2019. O papel do Estado numa Sociedade Internacional em transição: um debate para além das Relações Internacionais. Clareira, v.6, n.1-2.

MARQUES, R; GUEDES LEITE, M. 2016. Notas críticas sobre O Capital no século XXI de Thomas Piketty. Brazilian Journal of Political Economy/Revista de Economia Política, v. 36, n. 4.

MARX, K. 2013. Crítica da Filosofia do Direito de Hegel. São Paulo: Boitempo.

MARX, K. 1985. O Capital: crítica a economia política. Livro I. São Paulo: Nova Cultural.

PIKETTY, T. 2020. Capital and Ideology. Cambridge (MA): Harvard University Press.

PIKETTY, T. 2014. O Capital no Século XXI. Rio de Janeiro: Intrínseca.

SOUZA, J. 2006. A construção social da subcidadania: para uma sociologia política da modernidade periférica. Belo Horizonte: Editora UFMG/ Rio de Janeiro: IUPERJ.

STEINMETZ, G. 2011. Bourdieu, Historicity, and Historical Sociology. Cultural Sociology, v.5, n.45, pp.45-66.

TILLY, C. 1996. Coerção, Capital e Estados Europeus. São Paulo: Edusp.

VAROUFAKIS, Y. 2014. Egalitarianism's latest foe: a critical review of Thomas Piketty's Capital in the Twenty-First Century. Real-world Economics Review, n. 69, pp. 18-35.

WACQUANT, L. 2013. Poder simbólico e fabricação de grupos: como Bourdieu reformula a questão das classes. Novos estudos - CEBRAP, São Paulo, n. 96, pp. 87-103.

WALLERSTEIN, I. 1974. O sistema mundial moderno. Vol. I: a agricultura capitalista e as origens da economia-mundo europeia no século XVI. Porto: Ed. Afrontamentos.

WEBER, M. 2014. Politik als Beruf. Köln: Anaconda Verlag. 